\title{
What Causes Gastroesophageal Reflux Following Sleeve Gastrectomy?
}

\author{
Uwe J. Hesse ${ }^{1}$ \\ Published online: 14 November 2019 \\ (C) Springer Science+Business Media, LLC, part of Springer Nature 2019
}

\section{Dear Sir}

I read with great interest the article by Pilone V. et al. [1] Gastroesophageal reflux after sleeve gastrectomy (SG): new onset and effect on symptoms on a prospective evaluation.

The discussion was also fueled by M. Gagner's comment in JAMA Surgery on 3.7.2019 [2] on the revisions of gastric bypass as a moral obligation among others aiming on lower revisions rates for gastro esophageal reflux disease as compared to patients undergoing sleeve gastrectomy published by Hjorth et al. [3].

In both the article and the comment independently, the phenomenon of reflux esophagitis following bariatric surgery was elucidated and the ongoing debate of whether sleeve gastrectomy is a contraindication in patients with reflux disease remains appearently to be solved until the national randomized clinical study from Sweden comparing Roux-Y bypass with sleeve gastrectomy is published.

Among others, we have investigated and published our data on GERD following sleeve gastrectomy in 80 consecutive patients (mean BMI $49.5 \mathrm{~kg} / \mathrm{m}^{2}$ ) and we found a $76 \%$ reduction in 13/17 (i.e. cessation of therapy after 1 year and a mean 14 BMI points weight reduction) of preoperatively symptomatic patients requiring anti acid medication [3].

Likewise, 4 patients (24\%) continued to require PPI $(p<$ 0.0001 , chi-square test).

At the same time, 9/63 (14\%) of preoperatively asymptomatic patients developed de novo reflux esophagitis.

Uwe J. Hesse

Uwe.hesse@klinikum-nuernberg.de

1 Leiter Adipositas- und Metabolische Chirurgie, Klinikum Nürnberg, Paracelsus Medizinische Universität, Prof. Ernst-Nathan-str. 1, 90419 Nürnberg, Germany

This confirms that preoperative GERD is significantly ameliorated following sleeve gastrectomy due to weight loss and acid reduction. The potential risk of bile reflux due to impaired motility of the resected stomach however should be included when the real effects of SG on GERD are analyzed.

\section{Compliance with Ethical Standards}

Conflict of Interest The author declares that he has no conflict of interest.

\section{References}

1. Pilone V, Tramontano S, Renzulli M, et al. Gastroesophageal reflux after sleeve gastrectomy: new onset and effect on symptoms on a prospective evaluation1. Obes Surg 2019; https://doi.org/10.1007/ s11695-019-04046-5 .

2. Gagner M. Revision of gastric bypass- A moral obligation. JAMA Surg. 2019; https://doi.org/10.1001/jamasurg.2019.1740June 19 2019.

3. Hesse U, Stein $\mathrm{H}$ et al. The course of gastroesophageal reflux disease (GERD) following gastric sleeve resection in bariatric surgery Bariatric proceedings ISBN 978-88-7587-730-9 53-54 2016.

Publisher's Note Springer Nature remains neutral with regard to jurisdictional claims in published maps and institutional affiliations. 